\title{
A rare case of successful twin pregnancy in bicorporeal septate uterus with co-existent septate cervix
}

\author{
Srimathy Raman*, Shreelakshmi Gururaj, Ashwini J. Authreya, Padmalatha Venkataram
}

Department of Obstetrics and Gynecology, Rangadore Memorial Hospital, Shankarapuram, Bangalore, Karnataka, India

Received: 03 March 2021

Accepted: 06 April 2021

*Correspondence:

Dr. Srimathy Raman,

E-mail: ramansrimathy@gmail.com

Copyright: () the author(s), publisher and licensee Medip Academy. This is an open-access article distributed under the terms of the Creative Commons Attribution Non-Commercial License, which permits unrestricted non-commercial use, distribution, and reproduction in any medium, provided the original work is properly cited.

\begin{abstract}
Pregnancy occurring in patients with uterine malformations need to be managed with care as they are at risk of developing adverse outcomes. Multiple pregnancies in patients with uterine abnormalities further increase the risk of complications. Due to the rarity of this problem, there are no recommendations to guide and plan the management of these patients. Delivery planning is also tricky and needs to be individualised as either mode of delivery can be associated with complications. We discuss the management of a twin pregnancy in a primigravida (conceived after ovulation induction) with Mullerian abnormality- Septate uterus with co-existent septate cervix; ESHRE type U-2B C1.
\end{abstract}

Keywords: Multiple pregnancy, Uterine malformation, Bicorporeal uterus, Septate cervix, Delivery

\section{INTRODUCTION}

Congenital malformations of uterus can be present in 4-7\% of general population. They can be asymptomatic but can be associated with adverse reproductive and pregnancy outcomes and more so in patients with twin pregnancies. ${ }^{1}$ We report a case of twin pregnancy in complete septate uterus with co-existent septate cervix (ESHRE type: U-2 $\mathrm{B}, \mathrm{C}-1)$ with one pregnancy in each side of the septum conceived after ovulation induction.

\section{CASE REPORT}

A 27-year-old primigravida was seen at our hospital at 19 weeks of gestation for antenatal care and management of twin pregnancy. She conceived after treatment for PCOS related infertility (ovulation induction with clomiphene citrate $100 \mathrm{mg}$ ). She had her initial antenatal care at another hospital and Nuchal Translucency scan had revealed dichorionic diamniotic twin gestation. Her anomaly scan at our hospital revealed Bicornuate or possible septate uterus with two cervices with one pregnancy in each horn. Rest of the antenatal investigations were within normal limits.

Her pregnancy was followed up with two to three weekly antenatal visits, cervical length measurements at two-week intervals and interval growth scans at four weeks intervals. Her pregnancy was uneventful till the scan at 32 weeks of gestation which showed that one cervix was short with cervical length of $1.5 \mathrm{~cm}$ and an open internal os. The other cervix was normal with cervical length of $3.2 \mathrm{~cm}$. Growth scans were normal with satisfactory interval growth and liquor volume. In view of this, she was commenced on vaginal micronized progesterone $200 \mathrm{mg}$ daily and administered antenatal steroids.

The patient presented at 34 weeks of gestation with symptoms of preterm labour. She had two contractions in ten minutes. Both foetuses were in cephalic presentation and the foetal heart rate patterns of both foetuses were reassuring. Vaginal examination revealed two cervical openings with a septum and both about one $\mathrm{cm}$ dilated with vertex presentation and intact membranes. After 
counselling regarding limited evidence available to guide mode of delivery, decision was made for LSCS.

Intraoperatively, lower uterine segment was noted to be single and after an incision taken on it, the first twin was delivered. After delivery of first twin the septum was found to be bulging through the first incision. Incision was taken on the septum to deliver the second twin. Uterine incision was closed in 2 layers. Examination of the uterus and cavity confirmed the diagnosis of complete septate uterus (Figure 1). Both the babies were born with good Apgar scores and birth weight of $1.6 \mathrm{~kg}$ each. The patient made an uneventful recovery and was discharged on day 3.

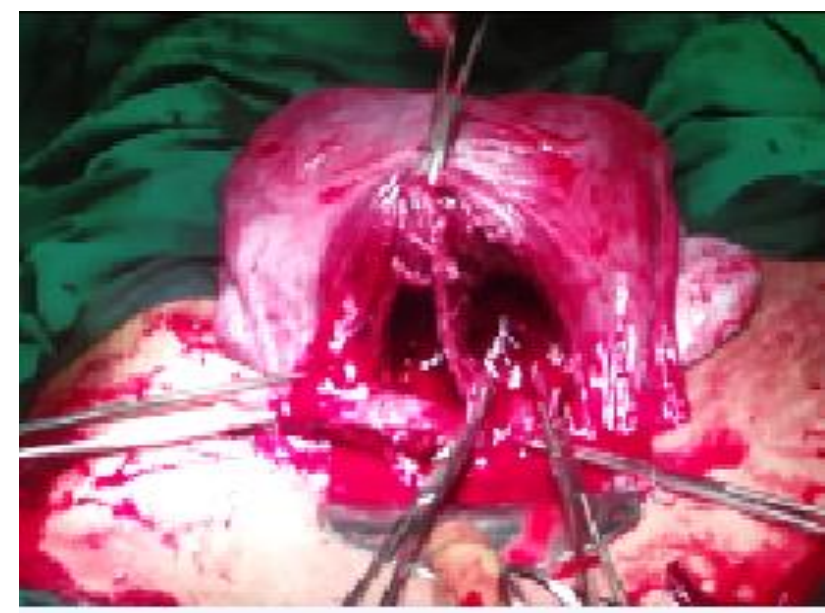

Figure 1: Complete septum seen dividing the uterine cavities.

\section{DISCUSSION}

Henonen in 1982 had noted that women with mullerian abnormalities have increased risk of pregnancy complications like miscarriage, premature labour, and delivery and foetal malpresentations. They can also however have a normal pregnancy and labour with good outcomes.

Congenital uterine anomalies comprise a wide spectrum of disorders and ASRM (American society for Reproductive Medicine) and ESHRE (European Society of Human Reproduction and Embryology) have proposed standard classification systems. According to ESHRE, Septate uterus incorporates all cases with normal fusion and abnormal absorption of the midline septum, and they are characterised by the uterus with normal outline and an internal indentation at the fundal midline exceeding $50 \%$ of the uterine wall thickness. The septum could be partial or complete and can include the cervix and/or vagina.

ESHRE defines bicorporeal uterus as all cases of fusion defects defined by the uterus having an abnormal fundal outline with the external indentation at the fundal midline exceeding $50 \%$ of the uterine wall thickness. According to ASRM, Septate uterus is one with a depth more than 1.5 $\mathrm{cm}$ from the interstitial line to the apex of the indentation and angle of the indentation $<90$ degrees.

Bicornuate has an external fundal indentation more than one $\mathrm{cm}$ with internal endometrial cavity like a septate uterus. C-1 or septate cervix incorporates all cases of cervical absorption defects characterized by the presence of a normal externally rounded cervix with the presence of a septum. Diagnostic methods include Hysterosalpingogram, 2D or 3D Ultrasound, combined hysteroscopy, and laparoscopy, sonohysterogram, 3D Ultrasound and MRI.

Our patient probably had a U-2 B, C-1 or a U-3, C-1defect as per the ESHRE classification. In septate-U2 the fundal outline is normal while our patient had an indentation (Figure 2) but to be classed as U-3 C an even greater indentation is needed. As per ASRM it could be classed as bicornuate uterus. Yanfang in 2016 discussed these problems faced in classification as the abnormalities may not strictly fit into one of the categories especially with the pregnancy changes that happen. ${ }^{1}$

Fox et. al noted the incidence of uterine anomalies in patients with twin pregnancies and singleton pregnancy to be similar at $3.1 \%$. They also found that the presence of a uterine anomaly in patients with twin pregnancies was significantly associated with adverse pregnancy outcomes specifically cerclage, preterm birth, and lower birth weights. Our patient had a preterm labour at 34 weeks. ${ }^{2}$

Shim et al did an analysis of seventeen twins with Mullerian abnormalities among Korean women in a tertiary hospital setting. They also looked at previous literature reporting multiple pregnancies in such women. They have been able to identify fourteen case reports reported previously in English language and including Fox et al (17 patients) they have discussed about 48 patients in total. The most common abnormality noted was septate uterus (20 patients but resected in 8 ) and ten are from bicornuate uterus. They however in contrast to Fox et al. noted no increase in adverse outcomes. ${ }^{3}$ Heinonen from Finland also reported on thirteen women with twin pregnancies associated with uterine malformations. They had three with septate uterus and two in uterine didelphys. They noted an increase in prematurity risks in these women. ${ }^{4}$ Maki et al in 2014 reported on eighteen twin pregnancies in association with uterine didelphys.

Incidence of twin gestation in association with uterine abnormalities is rare and so there are no guidelines on monitoring or deciding the mode of delivery of these patients. Both abdominal and vaginal deliveries are associated with risks and so management needs to be individualized. Crucyera et. al in 2011 noted that vaginal delivery may be associated with dystocia and even risks of uterine rupture while caesarean section also can be difficult with prolonged delivery times and bleeding risks. 
Given the uncertainties with trial for vaginal delivery, the couple in our case opted for LSCS.

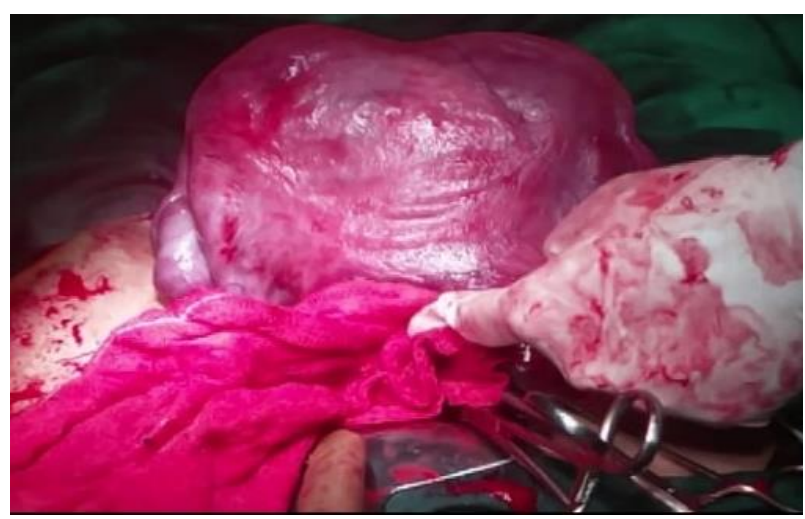

Figure 2: Fundal outline showing the indentation.

\section{CONCLUSION}

Prevalence and reproductive outcomes vary with different kinds of Mullerian abnormalities, though in general all increase the incidence of adverse outcomes. Septate uterus is thought to be the most common and there is a significant variation in the quoted complication rates. Reichman et. al in 2010 had noted that the outcomes are generally reported to be better with bicornuate uterus and with uterine didelphys than in unicornuate uterus. It is important to recognise these pregnancies as high risk and counselling; careful monitoring and individualised management plan are essential for successful outcomes.

\section{ACKNOWLEDGMENTS}

We thank the patient for giving her consent for publishing the case and for the images that are published.

Funding: No funding sources

Conflict of interest: The case report has been published as a poster in Bangalore Society of $O \& G$ Gnanavarsha conference, November 2017. The authors declare that there is no other conflict of interest.

Ethical approval: Not required

\section{REFERENCES}

1. Schöller D, Rall K, Brucker S. Congenital malformations, $\mathbf{J}$ of Obs. And Gynec. 2016;49(11):865-78.

2. Fox NS, Roman AS, Stern EM, Gerber RS, Saltzman $\mathrm{DH}$, Rebarber A. Type of congenital uterine anomaly and adverse pregnancy outcomes. J Matern Fetal Neonatal Med. 2014;27(9):949-53.

3. Shim S, Hur YM, Kim DH, Seong SJ, Kim ML, Shin JS. Evidence for No Significant Impact of Müllerian Anomalies on Reproductive Outcomes of Twin Pregnancy in Korean Women. Twin Res Hum Genet. 2016;19(2):146-53.

4. Heinonen PK. Twin pregnancy in the congenital malformed uterus. J Obstet Gynaecol. 2016;36(5):571-3.

Cite this article as: Raman S, Gururaj S, Authreya AJ, Venkataram P. A rare case of successful twin pregnancy in bicorporeal septate uterus with coexistent septate cervix. Int J Reprod Contracept Obstet Gynecol 2021;10:2096-8. 